\title{
Representação Cênica e Performance Acrobática - As Forças do Amor e da Magia
}

Scenical Representation and Acrobatic Performance
The Forces of Love and Magic

Mário Bolognesi ${ }^{1}$ 


\section{Resumo}

A feira de Saint-Germain acolheu, em 1678, o espetáculo As Forças do Amor e da Magia. A companhia Alard-Maurice foi a responsável pela encenação, que agregou acrobacia, funambulismo, dança e comédia. A peça apresenta características que estarão presentes na ópera-cômica, criação do Teatro de Feira, e nos espetáculos de atrações.

Palavras-chave: Teatro de Feira; Montagem de Atrações; Alard; Vondrebec
Abstract

In 1678, Saint-Germain's fair received the show The Forces of Love and Magic. The company Alard-Maurice was responsible for the staging that added acrobatics acts, rope balance, dancing and comedy. The spetacle has characteristics that will be present in the operacomic, the creation of the Fair Theater, and in the theater shows of attractions.

Keywords: Fair Theater, Montage of Attractions, Alard, Vondrebeck

E-ISSN: 2358.6958

\footnotetext{
Professor Doutor - Universidade Federal da Bahia (UFBA). Professor Visitante do PPGAC; Universidade Estadual Paulista (UNESP). Professor Colaborador do PPGA. Pesquisa desenvolvida com apoio da Fundação de Ampara à Pesquisa do Estado de São Paulo - FAPESP e Conselho Nacional de Desenvolvimento Científico e Tecnológico - CNPq. mario.f.bolognesi@gmail.com
} 


\section{Um enredo com acrobatas e atores}

O espetáculo As Forças da Magia e do Amor - Divertimento Cômico em Três Interlúdios, foi encenado em 1678, na Feira de Saint-Germain, Paris, pela companhia dos irmãos Alard, (Charles e Pierre)² que tinham como sócio o alemão Moritz von der Beek, ou Vondrebeck, (?-1694) conhecido como Maurice. A companhia era composta por vinte e quatro saltadores, dos mais variados países, entre os quais, Maurice, 0 mais habilidoso acrobata das feiras, naquela época. Além dos artistas dos saltos em solo e dos funambulistas, a encenação contou com três comediantes.

As personagens da peça são divididas em duas categorias: as que representam personagens e fazem uso de diálogos e as que se dedicam aos saltos acrobáticos e ao funambulismo. Dentre as primeiras, encontram-se Zoroastro, um feiticeiro, que a todo custo quer ter Gresinda, uma pastora, como amante. Para tanto, recorre à ajuda de seu criado Merlin. As personagens acrobáticas são as seguintes: Vários Saltadores sobre pedestais, Quatro Saltadores como Demônios, Quatro Saltadores como Pastores e Quatro Saltadores como Polichinelos.

Não há informações suficientes para confirmar o nome dos artistas participantes da encenação, nem ao menos para designar aqueles que se empenharam na representação de papéis. Não há, igualmente, como certificar se a pastora Gresinda tenha sido representada por uma atriz ou por um ator. Lembre-se, todavia, que as companhias teatrais que se formaram, a partir de 1640, nos teatros das feiras contavam com mulheres em sua composição. Merlin, segundo Spaziani, provavelmente tenha sido interpretado por Charles Alard (1982, p. 10). Essa personagem é a responsável pela parte cômica e pela ação dinâmica da peça; Zoroastro e Gresinda são duas personagens classificadas por Spaziani como "dramáticas e conectivas" $(1982$, p. 10)

O texto está dividido em três interlúdios e doze cenas. O enredo é simples e linear. Merlin procura Gresinda para comunicar o desejo de seu mestre, o mago Zoroastro, de um encontro íntimo com ela. Para isso, seria preparada uma recepção especial na residência do mago. Gresinda, inicialmente, rejeita o convite, assim como repele qualquer possibilidade de aproximação amorosa com Zoroastro. Merlin se deixa curvar pelos sentimentos de Gresinda e se propõe a ajudá-la. Ao notar a demora de Merlin em concluir o serviço pedido, Zoroastro, com base em seus poderes mágicos, envia um grupo de Demônios para aplicarem uma surra em Merlin. Este se apressa em dizer a Gresinda que aceite o convite.

Merlin, após a surra, retorna à casa de Zoroastro, que, auxiliado pelos Demônios, prepara a poção mágica que fará com que Gresinda se submeta aos seus desejos. Merlin, a todo instante, procura desviar o mestre de seu intento, dizendo que conheceu uma linda feiticeira, mas sem sucesso. Gresinda chega à casa do mago. 0 encontro é festejado com várias danças dos Saltadores. Gresinda quer ver a magia preparada por Zoroastro. O texto a descreve nos seguintes termos:

2 Quando possível, serão indicadas as datas de nascimento e morte, entre parênteses. Obras dos séculos XVIII e XIX, no entanto, não trazem esses indicadores. 
O mago manda trazer uma mesa e com sua varinha faz conjuras e círculos. Em seguida, ele levanta três taças que estão nessa mesa, mostra-as e coloca-as de volta; levantando-as, ele tira dali três macacos que dão muitos saltos e alinham-se ao lado do Teatro. Ele pega a taça do meio, mostra-a e coloca-a de volta, ele levanta-a, e tira uma torta, da qual vê-se voar muitas serpentes aladas. Na sequência, ele bate na mesa com a varinha. Dois Demônios retiram a mesa e aparece um novo Demônio que executa saltos mortais com os macacos; esses saltos aterrorizam a Pastora que parece forçada a se render. ${ }^{3}$

Aparentemente, Gresinda manifesta sua rendição, mas pede duas horas para se recuperar do susto e ir até sua casa se preparar para o encontro final. Zoroastro ordena a retirada dos Demônios. Merlin acompanha Gresinda.

Ao iniciar o terceiro e último interlúdio, Gresinda manifesta seu desespero a Merlin, que propõe soluções bizarras e zombeteiras: mentir seu nome ou então se matar. Ao propor a morte, Merlin imediatamente retrocede: em sua opinião, é melhor Gresinda vir a ser mulher do mago do que ir morar no reino de Plutão, em outras palavras, ser morta. A referência a uma divindade da mitologia greco-romana, por parte de Merlin, induz Gresinda a recorrer a Juno, deusa protetora das mulheres e dos casamentos.

Eles retornam à casa de Zoroastro. Merlin, que executou a tarefa a contento, pede ao seu mestre um feitiço que o aproxime de sua mulher. Zoroastro se prontifica a atendê-lo. Gresinda se encontra com Zoroastro e este pede permissão para beijá-la. Nesse momento, Juno intercede e faz Gresinda desaparecer, colocando um Demônio em seu lugar. Merlin zomba de seu mestre.

$\mathrm{Na}$ cena final, Merlin está só e renuncia ao feitiço prometido por Zoroastro. Ele se convence a conquistar sua amada pela beleza e gentileza. Ele, então, enfatiza a lição aprendida: "Tudo por amizade e nada pela força"4. O espetáculo termina com Merlin dançando uma sarabanda com nove posturas.

\section{Espetáculo e texto no Teatro de Feira}

O texto/roteiro do espetáculo foi dado a conhecimento público pela primeira vez pelos irmãos Parfaict, François (1698-1753) e Claude (1700-1777), em suas Mémoires Pour Servir à l'Histoire des Spectacles de la Foire Par Un Acteur Forain, primeiro volume. (1743, p. 56-79). Após a publicação da peça nas Mémoires, diversas outras se sucederam. ${ }^{5} \mathrm{O}$ texto ora apresentado em língua portuguesa, com tradução de Ignez Barros de Lima, tomou por base a publicação de Marcelo Spaziani (1982, p. 191-197), que reproduz na íntegra, no idioma original, a edição dos irmãos Parfaict.

\footnotetext{
3 No original francês : Le Magicien fait apporter une table, et avec as baguette fait des conjurations et des cercles; ensuite il leve trois gobelets qui sont sur cette table, les montre, et les remet et les relevant, il em sort trois singes qui font quantité de sauts et se rangente à côté du Théâtre. II reprend le gobelet du milieau, le montre et le remet et le releve, et il em sort um pâté, duquel on voit voler quantité de serpens ailés. II donne ensuite um coup de baguette sur la table, deux Démons enlévent la table, et il paroît um nouveau Démonm qui faut des sauts périlleux avec les singes; ces sauts épouvantent la Bergère, qui semble forcée de se rendre. (Tradução de Ignez Barro de Lima).

4 "Tout par amitié et rien par force." (Tradução de Ignez Barro de Lima).

5 Almanach Forain, em 1773; Théâtre de la Foire, de Eugène D'Auriac (1878); Le Théâtre de la Foire, la Comédie Italienne et l'Opéra Comique, de Maurice Drack (1889); Il Teatro della «Foire» (1965) e Gli Italini alla «Foire» (1982), de Marcello Spaziani.
} 
Na edição de 1743 não consta autoria do texto. Spaziani considera Charles Alard como autor (1982, p. 4, nota 2 e p. 10). Maurice Drack (1889, p. 4) além de Charles, também aponta Maurice Vondrebeck como autor. Ou seja, são atribuições de autoria a posteriori, levada adiante por estudiosos do Teatro de Feira.

A obra dos irmãos Parfaict é de 1743, o que corresponde a uma distância temporal de 65 anos entre a encenação e a publicação. François Parfaict nasceu em 1698 e seu irmão Claude, em 1700. Portanto, seus testemunhos e observações pessoais do teatro feito nas feiras só se aplicam após a década de vinte do século XVIII (Guardenti, 1995, p. 27). Antes disso, os escritos dos irmãos só podem se reportar à memória oral ou escrita de personalidades (artistas ou público) que vivenciaram a Feira de Saint-Germain em 1678. Diante disso, a respeito da escrita de As Forças do Amor e da Magia, ao menos duas hipóteses podem ser aventadas: 1) o texto foi escrito décadas após a encenação do espetáculo, a partir da memória dos artistas ou do público da época; 2) ele foi escrito no momento da encenação e recolhido pelos irmãos Parfaict dentre os manuscritos dos dirigentes da companhia, ou mesmo dos artistas que participaram da encenação. Não há, até o momento, investigações aprofundadas que possam sanar essas dúvidas. Mas isso não inviabiliza a divulgação e o reconhecimento de um importante momento do Teatro de Feira, exatamente aquele que apresenta a conjunção entre os números acrobáticos e de equilíbrio dos saltimbancos e a representação de personagens com diálogos. A aproximação de performances acrobáticas e representação cênica veio a ser uma das propulsoras das experimentações levadas a cabo pelos profissionais do Teatro de Feira de Paris.

O texto e sua proposta de encenação apontam, na interpretação de Venard, que as ações cênicas das personagens são apenas pretexto para a intervenção das exibições performáticas dos números de saltos e de equilíbrio e dança de corda. Essas exibições eram os "verdadeiros suportes do espetáculo". (1985, p. 69) As Forças do Amor e da Magia podem ser tomadas como exemplo claro da construção de uma trama teatral que tem como base espetacular aquilo que era particular para as exibições das feiras, os acrobatas, ou melhor, os artistas saltimbancos e seus números de variedades.

No ano seguinte à encenação, em 4 de fevereiro, Luiz XIV deu ordens ao comissário de polícia para que concedesse à companhia dos irmãos Alard e de Maurice permissão para se apresentar na Feira Saint-Germanin com acrobacias diversas, intercaladas por pequenos diálogos. Vetava, no entanto a apresentação de canto e de dança. (Guardenti, 1995, p. 23 e Spaziani, 1982, p. 3-4). Com isso, as autoridades preservavam o privilégio do canto e da dança concedido à Academia Real de Música. Porém, no ano seguinte, em 18 de agosto de 1680, com a criação da Comédie Française, protegida pela realeza, a autorização da trupe de Alard e Maurice deixou de vigorar. A partir de então, as companhias oficiais (a francesa e a italiana) subvencionadas pelo rei, eram as únicas que detinham autorização para representar comédias dialogadas em Paris. Os teatros das feiras foram proibidos de apresentar espetáculos com falas e diálogos. Os números de variedades dos saltimbancos e o teatro de bonecos retomaram o predomínio das cenas dos teatros foraines.

Esse panorama veio a se modificar a partir de 1697. A construção de um espetáculo agregando variedades acrobáticas e representação teatral ganhará força e 
energia, nas feiras de Paris, a partir da supressão da companhia de atores italianos, a Comèdie Italienne, que deixou de ser subsidiada e protegida pela realeza. Alguns de seus componentes procuraram as feiras para dar continuidade à profissão. Uma vez nas feiras, os comediantes dell'Arte repassaram aos saltimbancos a arte de representar comédias à italiana e os artistas das variedades ensinaram suas habilidades aos atores e atrizes da extinta companhia. Esse encontro foi decisivo para o avanço de uma forma de espetáculo que não podia fazer uso da palavra e do diálogo, do canto e da dança. As falas, dialogadas ou não, continuaram a ser exclusividade da Comèdie Française; o canto e a dança, exclusivos da companhia do Opéra. A partir de 1697, portanto, o repertório, as personagens e o modo de representar dos comediantes italianos foram incorporados pelo teatro de feira. A feira e seus teatros tornaram-se herdeiros da Commedia dell'Arte, inclusive de seu público. (Venard, 1985, p. 57). Ou seja, em poucas palavras, as feiras impulsionaram sobremaneira suas incursões espetaculares e teatrais.

A chegada dos comediantes italianos e a absorção de seus procedimentos de cena não aniquilaram a atuação dos saltimbancos. Estes eram responsáveis por apresentar um corpo extracotidiano em situações de saltos e equilíbrios, em movimentos de solo ou aéreos. Ademais, na opinião de Isabelle Martin, diante da forte concorrência estabelecida entre as várias trupes que trabalhavam nas feiras, o enlaçar as tramas teatrais às variedades voltadas à distração tornou-se uma regra necessária à eficácia dos espetáculos (2002, p. 120). Os dramaturgos que atuaram no Teatro de Feira, a partir dos primeiros anos do século XVIII, não podiam ignorar as características das feiras em dois aspectos fundamentais: os artistas e suas habilidades disponíveis à criação e a necessidade que se impunha para a conquista do público. Assim, com malabaristas, acrobatas, domadores de animais, atores, cenógrafos, cenotécnicos, etc. os autores criavam um prototeatro que atraía nobres, burgueses, soldados, jornaleiros, lacaios e artesãos. Nos espetáculos das duas grandes feiras o corpo acrobático que transgride os limites dos movimentos cotidianos se mesclaram às cenas teatrais, criando uma teatralização da virtuosidade.

As características e originalidades do Teatro de Feira, que viriam a ser experimentadas a partir de 1697 e que veio a culminar na criação de um novo gênero, a ópera-cômica, teve um exemplar precedente. Duas décadas antes da expulsão dos italianos e da entrada deles na Feira, As Forças do Amor e da Magia lançavam as bases estruturais de um espetáculo fundado em atrações dos saltimbancos e representação ficcional. Performance acrobática e representação cênica se encontraram em um mesmo espetáculo. Em 1678, as personagens do divertimento cômico de Alard e Maurice não eram as personagens-máscaras italianas que viriam a prevalecer, a partir de 1697.

Os irmãos Parfaict defenderam a ideia segundo a qual a obra de Alard e Maurice era um primeiro exemplo de peça característica do Teatro de Feira, que viria a consolidar o futuro gênero ópera-cômica, criação genuína das feiras. (Parfaict, 1743, p. 56). Tal opinião é relativizada por Spaziani quando advoga que se trata apenas de um primeiro exemplo de divertimento cômico, muito incipiente, quando poucas cenas com personagens se fundem a exibições acrobáticas em uma estrutura dramática linear e episódica (1982, p. 4). Ou seja, para o pesquisador italiano As Forças do Amor 
e da Magia não se configuravam ainda como uma obra dramática (p. 5). Ele aponta que peças anteriores poderiam ocupar o lugar daquela de Alard e Maurice. Cita como exemplo a Comédie de Chansons, de 1640, que fora composta sob o princípio do vaudeville, isto é, em mosaicos (1982, p.7).

Os argumentos de Spaziani fundam-se em explícitos critérios dramatúrgicos do teatro forain, que foram experimentados a partir de 1697. Dada a distância temporal entre o espetáculo e a publicação do texto, ele levanta a questão se os irmãos Parfaict não teriam modificado e alterado a peça. Após as dúvidas quanto à fidelidade do texto para com o espetáculo, Spaziani disseca a obra tendo como horizonte os elementos fundamentais da pièce foraine e da futura ópera-cômica, a saber, personagens, diálogos (em prosa e em versos), o canto, a música e a dança. O canto não faz parte do roteiro e não há nenhuma indicação de música. Ou seja, segundo ele, a peça é um divertimento, uma representação pastoral-fantástica, próximo às farsas representadas comumente nas feiras. Ele reconhece as qualidades do texto quando aponta a sincronia entre as cenas de efeitos espetaculares com aquelas secundárias e preparatórias que encaminham o enredo (1982, p. 11). Termina por admitir que a obra foi composta de acordo com "as boas regras da tradição francesa" (1982, p. 12). Distante, portanto, da composição e interpretação à italiana, que só ocorrerá após 1697.

Migrando da análise dramatúrgica para a encenação e seus procedimentos espetaculares, As Forças do Amor e da Magia trazem, de modo incipiente, os principais ingredientes de um espetáculo de atrações que se desenvolve a partir de um enredo, de uma história contada. Essas características são fundamentais para a compreensão da dinâmica do teatro de variedades, do vaudeville e do espetáculo do circo moderno. Spaziani aponta a ausência de indicadores de música no texto. Porém, procurando compreender o espetáculo a partir da dramaturgia, a ausência de indicadores musicais no texto não significa necessariamente que não houvesse a presença da música, ao menos para a pontuação rítmica que a dança requeria. Os momentos acrobáticos e os deslocamentos coreográficos são presentes e característicos da peça. Eles evidenciam uma ampla e extensa movimentação cênica, uma agilidade que toma o conjunto tridimensional do espaço de encenação. Esses momentos feéricos se enriqueciam com a música. Os elementos visuais e sonoros se complementavam.

Acrobacia, dança, equilíbrio de corda, cenas de magia e representação cômica com personagens estão presentes na peça de Alard e Maurice. A evolução do Teatro de Feira, com sua organização comercial, enfrentando as disputas policiais e jurídicas com as companhias oficiais e seus privilégios, desenvolverão outras técnicas e expedientes cênicos em torno de formas não dialogadas de representação. Essas pantomimas e suas técnicas de representação, aliadas às atrações dos saltimbancos e aos números com animais adestrados serão absorvidas pelo espetáculo do teatro de variedades e pelo circo moderno. Norteadas por um enredo, As Forças do Amor e da Magia, em 1678, trouxe alguns desses elementos e os integrou em um espetáculo composto por performances acrobáticas e personagens em uma representação cômica. 


\section{Referências}

AURIAC, Eugène D'. Théâtre de la Foire, recueil de pièces représentées aux foires de Saint-Germain et Saint-Laurent, précédé d'un essai historique sur les spectacles français. Paris: Garnier, 1878.

DRACK, Maurice. Le Théâtre de la Foire, la Comédie Italienne et l'Opéra Comique. Recueil de pièces choisies jouées de la fin du XVIle. siècle aux premières années du XIXe. siècle avec étude historique, notes et tables chronologiques 1658-1720. Paris: Firmin-Didot, 1889. (Genève: Slatkine Reprints, 1970).

GUARDENTI, Renzo. Le Fiere del Teatro. Percorsi del Teatro Forain del Primo Settecento. Roma: Bulzoni, 1995.

MARTIN, Isabelle. Le Théâtre de la Foire. Des tréteaux aux boulevards. Oxford: Voltaire Foundation, 2002.

PARFAICT, François e Claude. Mémoires Pour Servir à l'Histoire des Spectacles de la Foire Par Un Acteur Forain. Paris: Briassom, 1743. 2 v.

SPAZIANI, Marcello. Il Teatro della "Foire". Dieci commedie di Alard, Fuzelier, Lesage, D'Orneval, La Font, Piron. Roma: Ateneo, 1965.

SPAZIANI, Marcello. Gli Italiani alla «Foire». Roma: Edizioni di Storia e Letteratura, 1982.

VENARD, Michele. La Foire Entre en Scène. Paris: Lib. Théâtrale, 1985.

Recebido em: 14/06/2019 Aprovado em: 13/07/2019 


\section{AS FORÇAS DO AMOR E DA MAGIA Divertimento cômico em três interlúdios 6}

\section{PERSONAGENS}

ZOROASTRO, Mago, amante de Gresinda.

GRESINDA, Pastora.

MERLIN, Criado de Zoroastro.

VÁRIOS SALTADORES sobre pedestais,

QUATRO SALTADORES como Demônios.

QUATRO SALTADORES como Pastores.

QUATRO SALTADORES como Polichinelos.

\section{INTERLÚDIO}

A decoração do Teatro representa uma grande floresta e vê-se nas laterais do Teatro uma quantidade de Saltadores em pedestais. Depois que os Oboés tocaram uma abertura muito agradável, aparece um Ator sob o nome de Merlin.

\section{CENA I \\ MERLIN, só}

Amor, amor, amor cachorro, amor atrevido, amor cafajeste; o quê! Nunca se tem descanso? Deus, é preciso ter nascido num Planeta tão infeliz, para ter nascido servo, e servo de um mestre mais diabo que o Diabo! Que gasta sua vida e tempo lendo Gramáticas, que só tem os feiticeiros como divertimento. Para comer, aprecia os guisados de víboras, sapos e crocodilos. Seria apenas meio ruim, mas, acima dessas lindas qualidades, ele está apaixonado. Ele ama uma Pastora; mas, não pôde, até agora, penetrar no coração desta pobre ovelha. Na verdade, ela não tem toda culpa, pois se ele se tornasse o mestre, em toda a música ela só escutaria uivos; seus belos olhos veriam apenas Demônios, Fúrias e Inferno, e seus belos dentes de marfim só se ocupariam em roer serpentes e cobras; é o único pensamento que me faz estremecer, pois me parece que estou cercado por esses Senhores. (Um sapo aparece). Aqui está um que me pede para jantar: ah! Senhor sapo, eu agradeço de todo meu coração, não tenho apetite. (Um demônio aparece num redemoinho). Aqui está um outro que me convida para andar. Senhor Astarolh, eu vos agradeço: meu Médico me proibiu o exercício. (Vê-se um Saltador que parece voar de um lado para o outro do Teatro). Eis um outro: ele é um dos criados do meu mestre. Eu demorei muito tempo, é preciso procurar por Gresinda e quitar a missão que o Mago me deu. (Ele faz um salto).

6 Tradução de Ignez Barros de Lima. Formação em Direito, pela UFP-PE. Professora de Francês, com experiência nas Alianças Francesas de Curitiba e de Maceió. Tradutora de Francês, em diversos domínios. Notas explicativas de Mário Bolognesi. 


\section{CENA II \\ GRESINDA - Merlin}

GRESINDA - Você me traz boas notícias?

MERLIN - Mais ou menos.

GRESINDA - Como!? Zoroastro não está curado de sua paixão extravagante?

MERLIN - Quer dizer, que ele está mais mimado, está mais mesquinho e mais apaixonado do que nunca por seu lindo e charmoso "coração"7.

GRESINDA - Diga-me, meu querido Merlin, é possível que você me abandone e não faça todos os seus esforços para me livrar deste importuno?

MERLIN - Você quer que eu fale claramente: Meu mestre é meu mestre, e seus Demônios são mais diabólicos do que os meus: quando tomo a liberdade de lhe dizer que seria melhor para ele amar uma Maga do que uma Pastora, porque, parece-me, a guarnição seria melhor combinada, se você fosse testemunha, amável Gresinda, das contorções e das caretas que meu Mago faz, você ficaria surpresa; e se eu persistir em querer servi-la, as pauladas virão, e eu serei tratado como uma criança polida.

GRESINDA - Isso não é nada; tenha paciência até o fim: não serei ingrata.

MERLIN - Meus ombros estão ao seu serviço tanto quanto eles possam, mas quando eles estiverem muito abatidos e muito cansados, você concordará, por favor, que eu me recuse a falar a seu favor. (Quatro Saltadores como Demônios aparecem).

GRESINDA - Deus, o que eu estou vendo! Misericórdia! Amor, tem piedade das minhas dores e salva-me de cair nas mãos de Zoroastro, a quem eu odeio mais do que a morte.

MERLIN - Ah! Pois é, aqui estou derrotado, como deveria; eles são os servos de meu mestre, a quem servem como espiões e que, na presença dele, vão me dar fortes e vigorosas garantias dessa verdade; eu ficarei feliz, se eles só me quebrarem duas ou três costelas. (Os demônios o espancam com passos figurativos). Ah! Senhores, devagar, eu vos peço, como camarada, poupem o espancamento: pense em você, Pastora, meu mestre te convida, esta noite, para um entretenimento que ele preparou; mostre-lhe uma boa aparência; agrade-o, nem que seja por obrigação, e se o seu coração não disser nada para ele, se eu estiver aturdido, eu te servirei com o que me restar. (Os demônios saem).

7 No original, "Fressure" e não "coeur". Fressure, remete ao conjunto formado pelo coração, baço, fígado e os pulmões de um animal no açougue. Em sentido figurado, tem-se a conotação da totalidade das entranhas, um sentido carnal, portanto, que induz à excitação dos desejos. 


\section{CENA III \\ MERLIN, só}

Ah! Demônios cruéis! Se eu fizer a viagem ao Inferno alguma vez, vou deixá-los todos enfurecidos; quebrarei as fechaduras das portas, destruirei os muros dos Champs-Elysées; queimarei todos os vossos louros, abrirei todos os túmulos, para que os mortos lhes deem quinhentos piparotes; eu mancharei Plutão ${ }^{8}$, farei careta para Rhadamanthus ${ }^{9}$, tomarei o lugar de Minos $^{10}$; insultarei Caron ${ }^{11}$, quebrarei todos os seus remos, farei com que o mar engula todos os transeuntes, e que Caron engula a ele mesmo. Cá estou eu quite, finalmente evitei a barbárie destes diabinhos. (Os demônios voltam). Mas eu não contei com meu anfitrião e vejo bem que estou destinado a morrer a pauladas; no entanto, devo salvar minha pele e, por astúcia ou habilidade, sair dessa situação detestável; mas, como fazer? (Merlin olha para os Saltadores em seus pedestais). Devo tomar o lugar de um desses Cavalheiros; mas para quem me dirigir? É você que eu quero; sua fisionomia me desagrada. (Ele faz descer um Saltador e pula para o lugar dele). Retire-se daí e deixe o lugar para Merlin que é um homem mais honesto do que você. (Os Demônios retornam e movem as estátuas fazendo passos figurativos). Na verdade, eu não sei mais nada, e vejo bem que nem meus ombros e nem meus braços são suficientes para me tirar desse caso. É preciso ainda quebrar o pescoço. Ah, maldita magia! Maldita magia! Maldito destino! (Aqui todos dão saltos perigosos). Saltemos e morramos como homens de honra.

\section{INTERLÚDIO \\ CENA 1 \\ ZOROASTRO - Merlin}

ZOROASTRO - Merlin, Merlin!

MERLIN - Em que posso agradar, senhor?

ZOROASTRO - Vá ao meu gabinete, traga meu livro, um fogão, umas garrafas e tudo o que encontrar na minha mesa.

MERLIN - Eis aqui, justamente uma preparação para agradar Gresinda; e o senhor vai trabalhar para encantá-la de maneira bonita (À parte) Pobre Pastora, como tenho pena dela! (Ele sai).

\footnotetext{
8 Deus do mundo subterrâneo, na mitologia romana. Corresponde a Hades, na mitologia grega.

9 Radamanthus, ou Radamanto, era umegava as almas dos mortos sobre as águas do Estige e Aqueronte, rios que dividiam o mundo do dos juízes dos mortos, na mitologia grega. Ele era semi-deus, filho de Zeus e da princesa fenícia Europa.

10 Na mitologia grega, Minos, rei da llha de Creta, era irmão de Radamanthus.

11 Caron, ou Caronte, era o barqueiro de Hades, que carrs vivos do mundo dos mortos.
} 


\section{CENA II \\ ZOROASTRO, só}

É isso, bela Gresinda, é neste momento que acabarei com seus rigores, e os Demônios prometeram me servir de uma maneira que você não será capaz de se contrapor. E você, Amor, que me feriu com suas flechas mais penetrantes, complete seu trabalho e faça com que minha Pastora seja tocada pela minha paixão. Eu me comprometi a agradá-la; eu quero manter minha promessa e finalmente vencer ou perecer. (Os Demônios trazem a mesa e tudo o que o Mago pediu).

\section{CENA III ZOROASTRO - MERLIN}

MERLIN - Está tudo aqui, Senhor, aqui está a butique, aqui estão as cerâmicas, aqui estão os ingredientes. (À parte). Eis os demônios que podem levar você embora. (Alto). Pelo menos faça o molho tão bom que todos possam comer.

ZOROASTRO - Não se preocupe, quero tratá-la adequadamente e mostrar-lhe que Zoroastro sabe como alcançar seus planos. A Pastora não quis entregar-se às minhas submissões; eu me servirei da força da minha magia. (Ele prepara seu encanto)

MERLIN - Ah! Senhor, eu vi uma Maga linda!

ZOROASTRO - (sem escutá-lo) Como minha Pastora é amável!

MERLIN - Mas, Senhor, o senhor não quer mais ouvir ...

ZOROASTRO - Cale a boca, atrevido, ou meus criados ...

MERLIN - De fato, o senhor deve pagar salários muito bons para eles vos servirem com tanta precisão em tudo que o senhor lhes encomenda, como fizeram com minhas pobres costas. Eles obedeceram enormemente ao Senhor, eu sou a prova disso, um pouco rudemente, na verdade.

ZOROASTRO - (rindo). É para você aprender a lição e não demorar tanto tempo a fazer o que ordeno.

MERLIN - (apontando a chegada de Gresinda) Não pode ser mais justo nem mais lógico. Veja. 


\section{CENA IV \\ GRESINDA - ZOROASTRO - MERLIN}

ZOROASTRO - (abordando Gresinda) Eu sou grato, amável Pastora, pela sua visita; era para eu ir até você fazer meu dever de casa, renovar a oferta dos meus serviços e do meu coração; mas você sabe que minhas ocupações me eximem de sair deste retiro que os Deuses me concederam para minha estada, apenas com a condição de que eu nunca o deixe; estou muito feliz, já que você escolheu o mesmo lugar para passar seus dias solitários, e ficaria ainda mais, se você quisesse fazer a felicidade de Zoroastro.

GRESINDA - Eu devo a você todos esses sentimentos, mas contente-se com a minha estima; e uma vez que você me convidou para ver o entretenimento que me preparou, eu venho participar, e trago comigo alguns Pastores que, através de seus passos, deixarão com você, antecipadamente, as marcas de minha gratidão.

(Quatro saltadores como Pastores dançam uma Entrada).

ZOROASTRO - Nada é tão agradável; mas meu amor e meus respeitos não poderão quebrar a dureza do seu coração?

(Um Dançarino dança uma Entrada, os Pastores dançam uma outra, em seguida um Saltador como Arlequin dança um Jiga ${ }^{12}$ )

MERLIN - (fala baixo a Gresinda). Fique firme ou renda-se; escolha, porque, com certeza, você verá um belo jogo e, antes de tudo, não deixe de comer nosso jantar.

GRESINDA - (a Zoroastro). Deixe-me ver então o que você preparou para mim.

(O mago manda trazer uma mesa e com sua varinha faz conjuras e círculos. Em seguida, ele levanta três taças que estão nessa mesa, mostra-as e coloca-as de volta; levantando-as, ele tira dali três macacos que dão muitos saltos e alinham-se ao lado do Teatro. Ele pega a taça do meio, mostra-a e coloca-a de volta, ele levanta-a, e tira uma torta, da qual vê-se voar muitas serpentes aladas. Na sequência, ele bate na mesa com a varinha. Dois Demônios retiram a mesa e aparece um novo Demônio que executa saltos perigosos com uns macacos; esses saltos aterrorizam a Pastora que parece forçada a se render).

GRESINDA - Isso é o bastante, vejo bem que é preciso que eu ceda, à força, já que, para evitar minha morte, é preciso render-me, peço-lhe que expulse seus Demônios e me dê tempo para falar com você.

12 Antiga dança popular de ritmo animado, de origem anglo-saxónica. 
ZOROASTRO - (diz aos Demônios). Voltem para suas masmorras; vão, estou contente; a Pastora está serena, e eu estou muito feliz.

(Os Demônios e os Macacos dão novos saltos e vão embora).

MERLIN - (rindo). Isso é o que se chama, num bom francês, fazer-se amar a pauladas.

ZOROASTRO - Bem, Pastora, o que devo esperar?

GRESINDA - Tudo o que você quiser. Eu só peço duas horas para me recuperar do meu susto. Eu vou para a minha cabana, e volto.

ZOROASTRO - Deuses! Como estou contente! Merlin acompanhe minha Pastora e não a deixe.

(Quatro Saltadores como Polichinelos fazem uma Entrada que termina este segundo Interlúdio).

\section{INTERLÚDIO CENA I}

\section{GRESINDA - MERLIN}

GRESINDA - Eu prometi e me comprometi contra a minha decisão e contra os sentimentos do meu coração. Merlin estou desesperada; aconselhe-me.

MERLIN - Diga a ele que você é Normanda.

GRESINDA - Não zombe, peço a você, e diga-me o que eu devo fazer.

MERLIN - Mate-se, você se livrará disso; mas não, é melhor ser a esposa de um feiticeiro do que se tornar moradora na casa de Plutão.

GRESINDA - (depois de ter sonhado um pouco) Espere, eu ainda posso recorrer a Juno ${ }^{13}$. Ela terá pena dos meus males; ela nunca me abandonou, eu tenho certeza disso; vá encontrar o Mago, divirta-o e eu volto.

13 Na mitologia romana, Juno, esposa de Júpiter, era a deusa protetora das mulheres e dos casamentos. 


\section{CENA II \\ ZOROASTRO - MERLIN}

MERLIN - Aqui está tudo. Senhor, a Pastora é moça de palavra; ela tinha prometido, e o senhor sabe que as mulheres nunca faltam.

ZOROASTRO - (com ar de contentamento). Deixaram-me feliz, meus Demônios cumpriram o seu dever e serviram-me bem.

MERLIN - Se o senhor quiser, pelo meu salário, fazer algum pequeno feitiço para obrigar minha amante a amar o pobre Merlin, eu ainda serviria ao senhor de bom grado, por seis meses acima do nosso trato.

ZOROASTRO - Eu quero muito isso, e não custará nada além de me servir bem; siga-me e você ficará feliz.

\section{CENA III \\ GRESINDA, sozinha}

Juno prometeu me socorrer e eu venho receber as garantias.

\section{CENA IV \\ ZOROASTRO - GRESINDA - MERLIN}

ZOROASTRO - Aqui está, encantadora Pastora, aqui está o dia feliz em que meus desejos serão satisfeitos. Permita que eu beije você.

(A Pastora desaparece e, em seu lugar, um Demônio dá um salto do alto da arcada).

MERLIN - De fato, desta vez, a Pastora está sendo mais Bruxa do que o senhor; o senhor foi pego e ela, pelo menos, está sendo muito bem servida.

ZOROASTRO - (depois de ter sonhado). Eu sou a causa disso, Merlin; os Deuses se meteram neste assunto e eu estou sendo punido pela violência que eu quis fazer à Pastora. 


\section{ÚLTIMA CENA \\ MERLIN, sozinho.}

Na verdade, eu me atenho a esta máxima: Tudo por amizade e nada pela força. Eu renuncio ao feitiço que o Mago quer fazer para mim, e quero encantar minha amada, apenas com minha beleza e minha gentileza.

Ele dança uma Sarabanda de nove posturas, cujos nomes são: 1) A escadaria. 2) O berço. 3) A fonte. 4) A estrada principal. 5) O farol. 6) A pirâmide. 7) As vigas. 8) As forças da magia. 9) A grande postura. 